\title{
Marital status independently predicts prostate cancer survival in men who underwent radical prostatectomy: An analysis of 95,846 individuals
}

\author{
TIAN-BAO HUANG ${ }^{1,2^{*}}$, GUANG-CHEN ZHOU ${ }^{1,2^{*}}$, CHUAN-PENG DONG $^{3}$, LI-PING WANG $^{4}$, YANG LUAN $^{1,2}$, \\ JING-TING YE ${ }^{5}$, XIAO GU ${ }^{1,2}$, XU-DONG YAO ${ }^{6}$, JUN-HUA ZHENG ${ }^{6}$ and XUE-FEI DING ${ }^{1,2}$ \\ ${ }^{1}$ Department of Urology, Northern Jiangsu People's Hospital; ${ }^{2}$ Department of Urology, \\ College of Clinical Medicine, Yangzhou University, Yangzhou, Jiangsu 225001; ${ }^{3}$ Department of Biochemistry \\ and Molecular Biology, Institute of Biomedical Science, Shanghai Medical College, Fudan University, \\ Shanghai 200032; ${ }^{4}$ Department of Biobank, Northern Jiangsu People's Hospital; ${ }^{5}$ Department of Cardiothoracic Surgery, \\ College of Clinical Medicine, Yangzhou University, Yangzhou, Jiangsu 225001; ${ }^{6}$ Department of Urology, \\ Shanghai Tenth People's Hospital, Tongji University, Shanghai 200072, P.R. China
}

Received June 22, 2016; Accepted August 10, 2017

DOI: $10.3892 / \mathrm{ol} .2018 .7964$

\begin{abstract}
Marital status is an independent prognostic factor for survival in several types of cancer, but has not been fully studied in prostate cancer (PCa). A total of 95,846 men diagnosed with $\mathrm{PCa}$ were treated with radical prostatectomy (RP) between 2004 and 2009 within 18 Surveillance, Epidemiology and End Results registries. Survival curves were generated using Kaplan-Meier estimates and differences in survival were assessed using the log-rank test. Cox regression models were used to assess the impact of marital status on survival outcomes. The results demonstrated that the 8 -year cancer-cause specific survival (CSS) rate of married men was higher than unmarried individuals. Further analyses revealed that divorced/separated men had a higher proportion of high Gleason scores (GS) PCa at diagnosis [hazard ratio (HR), 1.12; $\mathrm{P}=0.007$ ] and those patients had the worst survival outcomes independent of age, ethnicity, grade, stage and sequence number [HR, 1.61; 95\% confidence interval (CI), 1.34-1.93]. Interestingly, it was observed that CSS among divorced/separated men decreased as the GS increased (GS $\leq 6$ : HR, 2.5; GS=7: HR, 1.71; GS $\geq 8$ : HR, 1.50; all $\mathrm{P}<0.05)$. Apart from that, no significant differences in CSS were observed in those who had never been married (HR, 1.20) or were widowed $(\mathrm{HR}, 1.13)$ relative to the married group. The results
\end{abstract}

Correspondence to: Professor Xue-Fei Ding, Department of Urology, Northern Jiangsu People's Hospital, 98 West Nantong Road, Yangzhou, Jiangsu 225001, P.R. China

E-mail: dingxf_sbyy@163.com

${ }^{*}$ Contributed equally

Key words: marital status, prostate cancer, radical prostatectomy, Surveillance, Epidemiology and End Results, Gleason score of the present study support the hypothesis that marital status is an independent prognostic factor among men with $\mathrm{PCa}$ who underwent RP. It was demonstrated that the mortality rates of divorced or separated men with PCa were significantly greater compared with the other groups. A further understanding of the potential associations among marital status, psychosocial factors and survival outcomes may help in developing novel, more effective methods of treating different groups of patients with PCa.

\section{Introduction}

Socioeconomic and demographic factors, including marital status, have a marked effect on the survival of patients with various diseases. Compared with married patients with cancer, patients with cancer who have never married, including divorced, separated or widowed, exhibit shorter overall survival (OS) and higher mortality rates (1-4). Previous studies have described the importance of marital status on the outcomes of patients with different types of cancer (4-7). However, the influence of marital status on the survival rates of patients with prostate cancer (PCa) remains controversial.

Two large-scale population-based studies, based on the Surveillance, Epidemiology and End Results (SEER) database, indicated that patients who were separated/divorced/widowed (SDW) exhibited higher cancer-specific and overall mortality rates $(8,9)$. Similarly, another study (10) consisting of 3,570 patients with $\mathrm{PCa}$ treated in three prospective Radiation Therapy Oncology Group clinical trials revealed that the survival rates of unmarried individuals were significantly decreased compared with married individuals. However, a study by Schiffmann et al (11) using the Martini-Klinik Prostate Cancer database indicated that married men with PCa did not have a significantly higher OS rate compared with SDW men over follow-up period of 48 months.

It has been demonstrated that the cancer-specific mortality rate for PCa differs significantly between married and SDW 
individuals. However, there are no significant differences in mortality rates between married individuals and those that have never been married [hazard ratio (HR), 1.03; 95\% confidence interval (CI), 0.91-1.17] (8). Li et al (7) revealed that widowed patients had the lowest survival rate among patients with colorectal cancer (HR, 1.49, 95\% CI, 1.45-1.53). Furthermore, no clear differences were observed between divorced/separated and married patients with pancreatic cancer at any stage in cause-special survival (CSS) (12). All of these indicate that the heterogeneity of unmarried individuals may somewhat influence the predictive value. However, previous studies (8-11) compared the survival outcomes of patients with PCa in terms of marital status without differentiating separated, divorced and widowed status. Several of these studies (9-11) did not even distinguish between patients that had never married and those that were SDW. In addition, the proportion of married individuals in the population, the prostate specific antigen (PSA) based screening strategy, mortality rate, surgical equipment, as well as the guidelines, including AUA (13) and EAU (14,15), have changed, which may affect the impact of marital status on patient outcomes $(16,17)$.

In the United States, $\mathrm{PCa}$ is the most commonly diagnosed type of non-skin cancer and the second leading cause of cancer-associated mortality in men (18). Marriage remains an important part of many people's lives, therefore, data from the SEER database was used to determine the aspects of marital status that affect OS and CSS in patients with $\mathrm{PCa}$ who underwent radical prostatectomy (RP).

\section{Patients and methods}

Patients. The current SEER database (November 2015 submission; http://seer.cancer.gov/), consisting of 18 population-based cancer registries, represents $\sim 28 \%$ of the entire population in the United States. The SEER*Stat (National Cancer Institute SEER*Stat software, version 8.3.2; http://www.seer.cancer.gov/seerstat/) was used to identify a cohort of patients with PCa with known marital status who underwent RP between 2004 and 2009. The inclusion criteria were as follows: i) Diagnosis of PCa confirmed by histology; ii) age at diagnosis, $>18$ years old; iii) presence of a single $\mathrm{PCa}$ or PCa as the first of $\geq 2$ primary cancers; and iv) the cause of mortality and survival time were documented. Additionally, only patients with prostate adenocarcinomas, including 8,140 , $8,141,8,143,8,255,8,260,8,310$ and 8,323 , as classified by the International Classification of Diseases for Oncology, 3rd edition morphology codes system (19) were included in the present study. Patients reported by a death certificate or autopsies were excluded. Data regarding patients included in the SEER database contain no identifiers and are publicly available for cancer-based analyses. Therefore, extra informed consent from patients and ethics committee approval were not required.

Patient clinicopathological characteristics. Clinicopathological parameters, including age at diagnosis, ethnicity, year of diagnosis, grade, SEER historic stage A, sequence number, Gleason score (GS), marital status, cause of mortality and survival months were extracted from the SEER database. According to the SEER staging system, patients were categorized as localized or regional, or distant or unstaged. Within the SEER database, marital status was recorded at the time of diagnosis. Patients were categorized as married, divorced, widowed, separated or never married. In the present study, separated and divorced individuals in the separated and divorced groups were combined into a divorced/separated group.

Statistical analysis. Two-sided $\chi^{2}$ tests were used to compare patient baseline characteristics in different marital status groups. As to follow-up time, one-way analysis of variance and a post hoc test by Dunnett's test were used to compare the difference. Survival curves were generated using Kaplan-Meier estimates and differences in the survival rates were assessed using the log-rank test. The impact of marital status and other clinicopathological parameters on survival outcomes were evaluated by building multivariable Cox regression models. The primary endpoint of the present study was CSS. PCa-associated mortality was treated as an event and mortality from other causes was treated as a censored observation. The secondary endpoint was OS. All statistical analyses were performed using the statistical software package SPSS for Windows, version 19 (SPSS, Inc., Chicago, IL, USA). All P-values were two tailed and $\mathrm{P}<0.05$ was considered to indicate a statistically significant difference.

\section{Results}

Patient characteristics. In total, 95,847 men with a histologically confirmed diagnosis of PCa who underwent RP between 2004 and 2009 were included in the present study. Of these, $78,244(81.6 \%)$ were married, 9,072 (9.5\%) were single, $6,627(6.9 \%)$ were divorced/separated and 1,903 (2.0\%) were widowed (Table I). The mean follow-up time was 78.3 (22.8) months. Men in the married group had the longest follow-up time compared with the other three groups (all $\mathrm{P}<0.05)$. The widowed group contained a significantly higher $(\mathrm{P}<0.05)$ number of elderly patients ( $\geq 66$ years old), a higher proportion of patients with distant disease and a higher proportion of patients with a high GS (Gleason score, $\geq 8$ ).

Marital status and OS. The 8-year OS was 93\% in the married group, $91 \%$ in the never married group, $88 \%$ in the divorced/separated group and $86 \%$ in the widowed group $(\mathrm{P}<0.001)$. Several other covariates, including an age $\geq 66$ years old $(\mathrm{P}<0.001)$, African-American ethnicity $(\mathrm{P}<0.001)$, poorly or undifferentiated tumor grade $(\mathrm{P}<0.001)$, distant disease $(\mathrm{P}<0.001)$, high GS $(\mathrm{P}<0.001)$ and the presence of $\geq 2$ primary types of cancer $(\mathrm{P}<0.001)$ were identified as significant risk factors for poor OS following univariate analysis. These covariates were further validated as independent prognostic factors using multivariate analysis (Table II). Compared with the married group, men in the three unmarried groups tended to exhibit worse OS (never married group: HR, 1.39, 95\% CI, 1.27-1.51; divorced/separated group: HR, 1.82, 95\% CI, 1.67-1.98; widowed group: HR, 1.69, 95\% CI, 1.47-1.93), following adjustment for age, ethnicity, tumor grade, tumor stage, GS and sequence number (Table II).

Marital status and CSS. Compared with the married group, men in the divorced/separated and widowed groups had a 
Table I. Baseline demographic and tumor characteristics of patients with PCa included in the SEER database between $2004-2009$.

\begin{tabular}{|c|c|c|c|c|c|c|}
\hline $\begin{array}{l}\text { Patient } \\
\text { characteristics }\end{array}$ & Total & $\begin{array}{l}\text { Married, } \\
\mathrm{n}(\%)\end{array}$ & $\begin{array}{c}\text { Never } \\
\text { married, n }(\%)\end{array}$ & $\begin{array}{c}\text { Divorced/separated, } \\
\mathrm{n}(\%)\end{array}$ & $\begin{array}{l}\text { Widowed, } \\
\text { n }(\%)\end{array}$ & P-value \\
\hline Cases & 95,846 & 78,244 & 9,072 & 6,627 & 1,903 & \\
\hline Age (years) & & & & & & $<0.001$ \\
\hline$\leq 50$ & 6,277 & $4,703(6.0)$ & $1,078(11.9)$ & $468(7.1)$ & $28(1.5)$ & \\
\hline $51-65$ & 64,529 & $52,525(67.1)$ & $6,320(69.7)$ & $4,793(72.3)$ & $891(46.8)$ & \\
\hline$\geq 66$ & 25,040 & $21,016(26.9)$ & $1,674(18.5)$ & $1,366(20.6)$ & $984(51.7)$ & \\
\hline Ethnicity & & & & & & $<0.001$ \\
\hline White & 79,211 & $66,002(84.4)$ & $6,605(72.8)$ & $5,086(76.7)$ & $1,518(79.8)$ & \\
\hline African-American & 11,431 & $7,785(9.9)$ & $2,049(22.6)$ & $1,305(19.7)$ & $292(15.3)$ & \\
\hline Other ${ }^{\mathrm{a}}$ & 5,204 & $4,457(5.7)$ & $418(4.6)$ & $236(3.6)$ & $93(4.9)$ & \\
\hline Grade & & & & & & $<0.001$ \\
\hline Well/moderately & 39,512 & $32,435(41.5)$ & $3,774(41.6)$ & $2,594(39.1)$ & 709 (37.3) & \\
\hline Poorly/undifferentiated & 56,200 & $45,710(58.4)$ & $5,281(58.2)$ & $4,022(60.7)$ & $1,187(62.4)$ & \\
\hline Unknown & 134 & $99(0.1)$ & $17(0.2)$ & $11(0.2)$ & $7(0.4)$ & \\
\hline SEER historic stage A & & & & & & 0.021 \\
\hline Localized/regional & 95,187 & $77,706(99.3)$ & $9,004(99.3)$ & $6,593(99.5)$ & $1,884(99.0)$ & \\
\hline Distant & 146 & $120(0.2)$ & $10(0.1)$ & $8(0.1)$ & $8(0.4)$ & \\
\hline Unstaged & 513 & $418(0.5)$ & $58(0.6)$ & $26(0.4)$ & $11(0.6)$ & \\
\hline Sequence number & & & & & & $<0.001$ \\
\hline One primary only & 88,407 & $72,070(92.1)$ & $8,466(93.7)$ & $6,162(93.0)$ & $1,709(89.8)$ & \\
\hline 1 st of 2 or more primaries & 7,439 & $6,174(7.9)$ & $606(6.7)$ & $465(7.0)$ & $194(10.2)$ & \\
\hline GS & & & & & & $<0.001$ \\
\hline$\leq 6$ & 36,893 & $30,386(38.8)$ & $3,468(38.2)$ & $2,400(36.2)$ & $639(33.6)$ & \\
\hline 7 & 45,581 & $37,074(47.4)$ & $4,367(48.1)$ & $3,216(48.5)$ & $924(48.6)$ & \\
\hline$\geq 8$ & 9,483 & $7,670(9.8)$ & $845(9.3)$ & $714(10.8)$ & $254(13.3)$ & \\
\hline Unknown & 3,889 & $3,114(4.0)$ & $392(4.3)$ & $297(4.5)$ & $86(4.5)$ & \\
\hline Follow-up (months) ${ }^{\mathrm{b}}$ & 78.3 & 78.7 & 76.6 & 76.8 & 77.0 & $<0.001$ \\
\hline
\end{tabular}

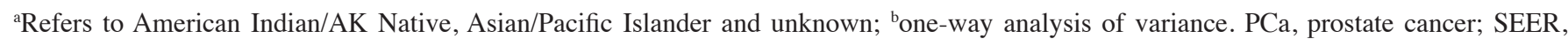
Surveillance, Epidemiology, and End Results; GS, Gleason score.

worse CSS $(\mathrm{P}<0.001, \mathrm{P}=0.001$, respectively $)$, while men in the never married group exhibited a similar CSS $(\mathrm{P}=0.134)$ according to log-rank test (Fig. 1A). Cox regression multivariate analysis of CSS was performed and revealed that the marital status and several other covariates remained as independent prognostic factors (Table II). Compared with young men and non-African-American men, elderly men and African-American men had poorer CSS (HR, 1.46, 95\% CI, 1.10-1.93; HR, 1.19, 95\% CI, 1.01-1.40, respectively). GS $\geq 8$ and combining with distant disease are predictive factors of worse cancer-specific mortality (HR, 11.42, P<0.001; HR.11.27, $\mathrm{P}<0.001$, respectively). In terms of the marital status, men in the divorced/separated group (HR, 1.61, 95\% CI, 1.34-1.93), but not in the never married or widowed group (HR, 1.20, 95\% CI, 1.00-1.44; HR, 1.13, 95\% CI, 0.81-1.58), had a poorer CSS, when compared with men in the married group, following adjustment for age, ethnicity, grade, stage, GS and sequence number.

Considering the effect of cancer stage and GS on CSS, subgroup analyses were performed to assess if they influenced the effect of marital status on CSS. The results demonstrated that marital status was not a valid risk factor among men with distant disease according to univariate and multivariate analyses $(\mathrm{P}=0.146$ and $\mathrm{P}=0.187$, respectively). However, among men diagnosed with localized/regional disease, marital status significantly affected CSS ( $\mathrm{P}<0.001$; Table III). Furthermore, marital status remained an independent prognostic factor in each GS group, as determined by univariate and multivariate analyses (Fig. 1B-D and Table IV). It was observed that the HR of CSS among divorced/separated men decreased when GS increased (GS $\leq 6$ : HR, 2.5, 95\% CI, 1.54-4.04; GS=7: HR, 1.71, 95\% CI, 1.24-2.36; GS $\geq 8$ : HR, 1.50, 95\% CI, 1.17-1.93; all $\mathrm{P}<0.05)$.

\section{Discussion}

The effect of marital status on the survival of patients with PCa who have undergone RP has been studied using SEER and the Martini-Clinic Prostate Cancer database $(8,11)$. However, the results of these investigations have not been consistent and no studies have been conducted focusing on 
Table II. Multivariate analysis evaluating the influence of marital status on OS and CSS.

\begin{tabular}{|c|c|c|c|c|c|c|c|c|}
\hline \multirow[b]{2}{*}{ Patient characteristics } & \multirow{2}{*}{$\begin{array}{c}\text { 8-year } \\
\text { OS }\end{array}$} & \multicolumn{2}{|c|}{$\begin{array}{c}\text { Multivariate } \\
\text { analysis }\end{array}$} & \multirow[b]{2}{*}{ P-value } & \multirow{2}{*}{$\begin{array}{c}\text { 8-year } \\
\text { CSS }(\%)\end{array}$} & \multicolumn{2}{|c|}{$\begin{array}{c}\text { Multivariate } \\
\text { analysis }\end{array}$} & \multirow[b]{2}{*}{ P-value } \\
\hline & & HR & $95 \% \mathrm{CI}$ & & & HR & $95 \% \mathrm{CI}$ & \\
\hline Age (years) & & & & $<0.001$ & & & & $<0.001$ \\
\hline$\leq 50$ & 96 & \multicolumn{2}{|c|}{ Reference } & & 99 & \multicolumn{2}{|c|}{ Reference } & \\
\hline $51-65$ & 94 & 1.65 & $(1.41-1.93)$ & & 98 & 1.07 & $(0.81-1.40)$ & \\
\hline$\geq 66$ & 87 & 2.90 & $(2.47-3.40)$ & & 97 & 1.46 & $(1.10-1.93)$ & \\
\hline Ethnicity & & & & $<0.001$ & & & & $<0.001$ \\
\hline White & 92 & \multicolumn{2}{|c|}{ Reference } & & 98 & \multicolumn{2}{|c|}{ Reference } & \\
\hline African-American & 89 & 1.54 & $(1.43-1.65)$ & & 98 & 1.19 & $(1.01-1.40)$ & \\
\hline Other $^{\mathrm{a}}$ & 94 & 0.85 & $(0.75-0.96)$ & & 99 & 0.56 & $(0.41-0.75)$ & \\
\hline Grade & & & & $<0.001$ & & & & $<0.001$ \\
\hline Well/moderately & 94 & \multicolumn{2}{|c|}{ Reference } & & 99 & \multicolumn{2}{|c|}{ Reference } & \\
\hline Poorly/undifferentiated & 91 & 1.16 & $(1.04-1.30)$ & & 97 & 1.58 & $(1.18-2.10)$ & \\
\hline Unknown & 73 & 2.29 & $(1.47-3.55)$ & & 90 & 4.79 & $(2.34-9.77)$ & \\
\hline SEER historic stage A & & & & $<0.001$ & & & & $<0.001$ \\
\hline Localized/regional & 92 & \multicolumn{2}{|c|}{ Reference } & & 98 & \multicolumn{2}{|c|}{ Reference } & \\
\hline Distant & 68 & 4.80 & $(3.60-6.40)$ & & 75 & 11.27 & $(8.03-15.82)$ & \\
\hline Unstaged & 86 & 1.47 & $(1.11-1.95)$ & & 96 & 1.75 & $(1.00-3.06)$ & \\
\hline Sequence number & & & & $<0.001$ & & & & $<0.001$ \\
\hline One primary only & 94 & \multicolumn{2}{|c|}{ Reference } & & 98 & \multicolumn{2}{|c|}{ Reference } & \\
\hline 1 st of 2 or more primaries & 69 & 5.76 & $(5.45-6.09)$ & & 96 & 1.95 & $(1.68-2.27)$ & \\
\hline GS & & & & $<0.001$ & & & & $<0.001$ \\
\hline$\leq 6$ & 94 & \multicolumn{2}{|c|}{ Reference } & & 99 & \multicolumn{2}{|c|}{ Reference } & \\
\hline 7 & 92 & 1.10 & $(0.98-1.24)$ & & 99 & 1.53 & $(1.12-2.10)$ & \\
\hline$\geq 8$ & 83 & 2.30 & $(2.03-2.62)$ & & 90 & 11.42 & $(8.31-15.70)$ & \\
\hline Unknown & 90 & 1.35 & $(1.14-1.61)$ & & 96 & 3.79 & $(2.61-5.52)$ & \\
\hline Marital status & & & & $<0.001$ & & & & $<0.001$ \\
\hline Married & 93 & \multicolumn{2}{|c|}{ Reference } & & 98 & \multicolumn{2}{|c|}{ Reference } & \\
\hline Never married & 91 & 1.39 & $(1.27-1.51)$ & & 98 & 1.20 & $(1.00-1.44)$ & \\
\hline Divorced/separated & 88 & 1.82 & $(1.67-1.98)$ & & 97 & 1.61 & $(1.34-1.93)$ & \\
\hline Widowed & 86 & 1.69 & $(1.47-1.93)$ & & 97 & 1.13 & $(0.81-1.58)$ & \\
\hline
\end{tabular}

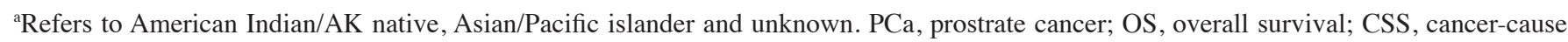
special survival; HR, hazard ratio; CI, confidence interval; SEER, Surveillance, Epidemiology, and End Results; GS, Gleason score; Reference, reference group.

the heterogeneity of unmarried patients. Therefore, the present study was performed to assess the effect of marital status on the outcomes of men with PCa. Multivariate analyses of 95,847 men revealed that marital status was an independent prognostic factor of OS and CSS. Compared with married men, divorced or separated men with PCa had a higher GS at diagnosis (HR, 1.12, 95\% CI, 1.03-1.22) and those patients exhibited the worst survival outcomes independent of age, ethnicity, grade, stage or sequence number. Due to the distributional discrepancies of GS, a grade-by-grade comparison was performed. Interestingly, the HR of CSS for divorced or separated men decreased when GS increased, compared with married men $(\mathrm{GS} \leq 6$ : $\mathrm{HR}, 2.5 ; \mathrm{GS}=7$ : HR: $1.71 ; \mathrm{GS} \geq 8$ : HR: 1.50 , respectively).
Several hypotheses have been proposed to explain the inferior survival outcomes of unmarried individuals. Divorced/separated men are more likely to be diagnosed with high grade PCa compared with married men (HR, 1.12, 95\% CI: 1.03-1.22, P=0.007). Furthermore, patients with PCa and high GS have poorer PCa-related survival outcomes $(20,21)$. However, this does not explain why the married and widowed patients, had a similar CSS. Psychosocial factors may account for such a difference in CSS; for example, married men may be encouraged by their spouses to choose a more curative therapy $(8,22,23)$.

It is known that men with cancer exhibit more severe psychological distress than those with other chronic health conditions (24). Separated and divorced individuals have a 
Table III. Univariate and multivariate analysis of marital status on prostate cancer-cause specific survival based on different SEER historic stages.

\begin{tabular}{|c|c|c|c|c|c|c|}
\hline \multirow[b]{2}{*}{ Marital status } & \multicolumn{2}{|c|}{ Univariate analysis } & \multirow[b]{2}{*}{ P-value } & \multicolumn{2}{|c|}{ Multivariate analysis } & \multirow[b]{2}{*}{ P-value } \\
\hline & $\mathrm{HR}$ & $95 \% \mathrm{CI}$ & & HR & $95 \% \mathrm{CI}$ & \\
\hline Localized/regional & & & $<0.001$ & & & $<0.001$ \\
\hline Married & \multicolumn{2}{|c|}{ Reference } & & \multicolumn{2}{|c|}{ Reference } & \\
\hline Never married & 1.14 & $(0.95-1.38)$ & & 1.20 & $(0.99-1.44)$ & \\
\hline Divorced/separated & 1.73 & $(1.45-2.08)$ & & 1.66 & $(1.39-1.99)$ & \\
\hline Widowed & 1.50 & $(1.06-2.11)$ & & 1.17 & $(0.83-1.65)$ & \\
\hline Distant & & & 0.187 & & & 0.146 \\
\hline Married & \multicolumn{2}{|c|}{ Reference } & & \multicolumn{2}{|c|}{ Reference } & \\
\hline Never married & 2.95 & $(1.13-7.68)$ & & 2.64 & $(0.96-7.23)$ & \\
\hline Divorced/separated & 0.61 & $(0.60-4.41)$ & & 0.42 & $(0.05-3.40)$ & \\
\hline Widowed & 1.25 & $(0.30-5.25)$ & & 0.72 & $(0.15-3.40)$ & \\
\hline
\end{tabular}

HR, hazard ratio; CI, confidence interval; SEER, Surveillance, Epidemiology, and End Results; Reference, reference group.
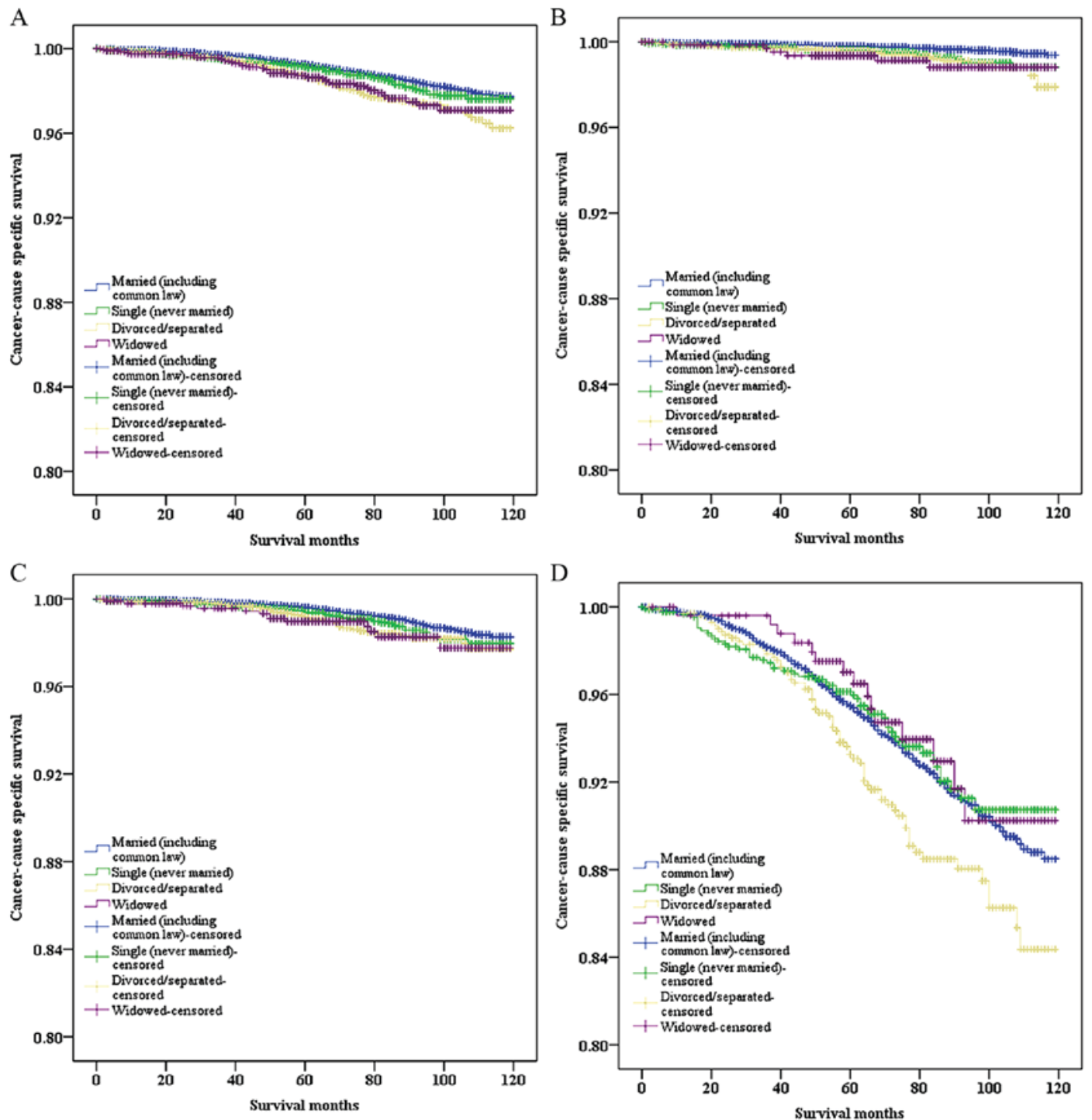

Figure 1. Survival curves in men with PCa who underwent radical prostatectomy according to marital status. (A) Survival curves in men with PCa regardless of GS. $\chi^{2}=38.986, \mathrm{P}<0.001$. (B) Survival curves in men with PCa and a GS of 2-6. $\chi^{2}=27.111, \mathrm{P}<0.001$. (C) Survival curves in men with PCa and a GS of 7 . $\chi^{2}=14.701, \mathrm{P}=0.002$. (D) Survival curves in men with $\mathrm{PCa}$ and a GS of $8-10 . \chi^{2}=9.946, \mathrm{P}<0.019$. PCa, prostate cancer; GS, Gleason score. 
Table IV. Univariate and multivariate analysis of marital status on prostate cancer-cause specific survival in terms of different GS range.

\begin{tabular}{|c|c|c|c|c|c|c|}
\hline \multirow[b]{2}{*}{ Marital status } & \multicolumn{2}{|c|}{ Univariate analysis } & \multirow[b]{2}{*}{ P-value } & \multicolumn{2}{|c|}{ Multivariate analysis } & \multirow[b]{2}{*}{ P-value } \\
\hline & HR & $95 \% \mathrm{CI}$ & & HR & $95 \% \mathrm{CI}$ & \\
\hline $\mathrm{GS} \leq 6$ & & & $<0.001$ & & & $<0.001$ \\
\hline Married & \multicolumn{2}{|c|}{ Reference } & & \multicolumn{2}{|c|}{ Reference } & \\
\hline Never married & 2.13 & $(1.37-3.33)$ & & 2.17 & $(1.39-3.41)$ & \\
\hline Divorced/separated & 2.54 & $(1.57-4.11)$ & & 2.50 & $(1.54-4.04)$ & \\
\hline Widowed & 2.80 & $(1.23-6.39)$ & & 1.75 & $(0.76-4.14)$ & \\
\hline $\mathrm{GS}=7$ & & & 0.002 & & & 0.002 \\
\hline Married & \multicolumn{2}{|c|}{ Reference } & & \multicolumn{2}{|c|}{ Reference } & \\
\hline Never married & 1.32 & $(0.97-1.81)$ & & 1.37 & $(1.00-1.88)$ & \\
\hline Divorced/separated & 1.67 & $(1.21-2.29)$ & & 1.71 & $(1.24-2.36)$ & \\
\hline Widowed & 1.73 & $(0.99-3.01)$ & & 1.45 & $(0.83-2.52)$ & \\
\hline $\mathrm{GS} \geq 8$ & & & 0.009 & & & 0.02 \\
\hline Married & \multicolumn{2}{|c|}{ Reference } & & \multicolumn{2}{|c|}{ Reference } & \\
\hline Never married & 0.92 & $(0.69-1.22)$ & & 0.91 & $(0.68-1.22)$ & \\
\hline Divorced/separated & 1.45 & $(1.13-1.86)$ & & 1.50 & $(1.17-1.93)$ & \\
\hline Widowed & 0.86 & $(0.52-1.44)$ & & 0.85 & $(0.51-1.42)$ & \\
\hline
\end{tabular}

HR, hazard ratio; CI, confidence interval; GS, Gleason score; Reference, reference group.

higher risk of distress [odds ratio (OR), 5.25; OR, 2.79, respectively], whereas married are less likely to experience distress, depression and anxiety $(24,25)$. In addition, being married is associated with higher perceived tangible and emotional support (both $\mathrm{P}<0.001$ ), which may influence follow-up care use by fostering a sense of obligation to manage one's health and encouraging access to medical care (26). Married men may also benefit from increased financial resources and better access to health insurance.

Psychosocial support may predict the prognosis of men with cancer (27), Garssen (28) summarized the results of 70 prospective studies and revealed that a low level of social support and chronic depression can predict unfavorable prognosis. Neurohormones and neurotransmitters (cortisol and norepinephrine), the vagal nerve and inflammation, DNA damage, interleukin-1 and oxytocin may be specific mediators in this potential association either by directly affecting tumorigenesis or indirectly affecting other factors, such as cellular immunity (27). It has been demonstrated that the activity of natural killer cells is low when an individual perceives a lack of social support (29), which may result in a failure to treat and control cancer (30).

In the present study, as well as 88,407 patients with a single primary $\mathrm{PCa}, 7,439$ patients with $>1$ primary cancer were also included. Among these patients, PCa was the first diagnosed type of cancer. In the multivariate analysis, it was observed that novel-onset cancer was associated with poorer OS and CSS (HR, 5.76; HR, 1.95, respectively), following adjustment for age, ethnicity, marital status, GS, stage and grade.

Compared with that in the married group, a higher proportion of patients in the widowed group had distant disease and a high GS (HR, 2.28, $\mathrm{P}=0.027$; HR, 1.23, $\mathrm{P}=0.005$, respectively); however they had a similar CSS when compared with the married group. By contrast, the results of previous studies investigating two other types of solid cancer demonstrated that widowed patients exhibited significantly poorer CSS $(7,12)$. Two possible reasons may explain this discrepancy. Firstly, 1,765 of 13,370 patients with pancreatic cancer and 21,279 of 112,776 patients with colorectal cancer were widowed in these two studies. However, in the present study, widowed men occupied a smaller fraction of the total cases $(1,903 / 95,846)$ and only 37 widowed men succumbed from PCa with a mean of 77 months' of follow-up, which made it hard to obtain positive observations. Secondly, 'widowed' in the present study only referred to widowed men, which was different from the definition of 'widowed' in the other studies investigating pancreatic and colorectal cancer. Therefore, the CSS of widowed patients with PCa should be further analyzed in a large-scale population.

The current study demonstrated that, among men with localized or regional PCa, marital status was an independent prognostic factor of CSS $(\mathrm{P}<0.001)$. However, among those diagnosed with distant $\mathrm{PCa}$, there was no difference in CSS among men with different marital status, as determined by univariate and multivariate analyses $(\mathrm{P}=0.146$ and $\mathrm{P}=0.187$, respectively). This may have been due to the small sample size, which only accounted for $0.152 \%$ of the total patients, which may make it more difficult to detect the effect of marital status on CSS in patients with PCa.

Although all data were derived from a large population-based study, several potential limitations should also be taken into consideration. Firstly, PSA levels in men diagnosed between 2004 and 2009 are currently being removed and reviewed for potential error. PSA was introduced as a component of staging 
in the 7th edition of American Joint Committee on Cancer (AJCC) in 2010 (31). It was difficult to convert from AJCC 6th to AJCC 7th; therefore, SEER historic stage A, which categorizes cancer as localized or regional, distant or unstaged, was used instead of the AJCC staging system. The SEER database does not collect information concerning education, insurance and income status, diet, or family status, all of which may influence the effect of the marital status on patient survival (9,32-35). Furthermore, the quality of marriage is hard to document, and the marital status may change over time. As the current study did not identify whether unmarried men lived with their partners, a more concrete conclusion could not be reached. Thirdly, information regarding comorbidities, including diabetes, hypertension, cardiovascular disease and several other chronic illnesses, which have been proven to exhibit an impact on cancer survival (36-38), were not included in the SEER database. Lack of these covariates may partial bias the observations of the present study.

To conclude, the results of the current study support the hypothesis that marital status is an independent prognostic factor of OS and CSS. Divorced or separated men are more likely to exhibit a higher GS PCa at diagnosis and the poorest survival outcomes independent of age, ethnicity, grade, stage and sequence number. This association between marital status and poor outcomes was maintained in each GS group. Psychosocial factors may be the main reasons for the poorer survival outcomes of divorced or separated men. Although patients in the widowed group had a higher proportion of patients with distant disease and high GS, they had a similar CSS compared with the married group. Considering the low proportion of widowed men included in the current study, a large-scale study involving widowed patients with $\mathrm{PCa}$ is required. Further understanding of the potential associations among the marital status, psychosocial factors, survival outcomes may help in identifying sound strategies of treating men with $\mathrm{PCa}$.

\section{Acknowledgements}

The present study used the linked SEER database. The authors acknowledge the efforts of the SEER program tumor registries in the creation of the SEER database. Besides, the authors would like to thank Lu Feng for revising the study. The present study was supported by Jiangsu Provincial Commission of Health and Family Planning (grant no. H201550).

\section{Competing interests}

The authors declare that they have no competing interests.

\section{References}

1. Kaplan RM and Kronick RG: Marital status and longevity in the United States population. J Epidemiol Community Health 60: 760-765, 2006

2. Hu YR and Goldman N: Mortality differentials by marital status: An international comparison. Demography 27: 233-250, 1990.

3. Kravdal O: The impact of marital status on cancer survival. Soc Sci Med 52: 357-368, 2001.

4. Aizer AA, Chen MH, McCarthy EP, Mendu ML, Koo S, Wilhite TJ, Graham PL, Choueiri TK, Hoffman KE, Martin NE, et al: Marital status and survival in patients with cancer. J Clin Oncol 31: 3869-3876, 2013
5. Hellenthal NJ, Chamie K, Ramirez ML and deVere White RW: Sociodemographic factors associated with nephrectomy in patients with metastatic renal cell carcinoma. J Urol 181: 1013-1019, 2009.

6. Pruthi RS, Lentz AC, Sand M, Kouba E and Wallen EM: Impact of marital status in patients undergoing radical cystectomy for bladder cancer. World J Urol 27: 573-576, 2009.

7. Li Q, Gan L, Liang L, Li X and Cai S: The influence of marital status on stage at diagnosis and survival of patients with colorectal cancer. Oncotarget 6: 7339-7347, 2015.

8. Abdollah F, Sun M, Thuret R, Abdo A, Morgan M, Jeldres C, Shariat SF, Perrotte P, Montorsi F and Karakiewicz PI: The effect of marital status on stage and survival of prostate cancer patients treated with radical prostatectomy: A population-based study. Cancer Causes Control 22: 1085-1095, 2011.

9. Tyson MD, Andrews PE, Etzioni DA, Ferrigni RG, Humphreys MR, Swanson SK and Castle EK: Marital status and prostate cancer outcomes. Can J Urol 20: 6702-6706, 2013.

10. Du KL, Bae K, Movsas B, Yan Y, Bryan C and Bruner DW: Impact of marital status and race on outcomes of patients enrolled in radiation therapy oncology group prostate cancer trials. Support Care Cancer 20: 1317-1325, 2012.

11. Schiffmann J, Beyer B, Tennstedt P, Boehm K, Mehring G, Schlomm T, Salomon G, Karakiewicz P and Graefen M: Oncological outcome after radical prostatectomy: Marital status does not make a difference. Int J Urol 22: 484-489, 2015.

12. Wang XD, Qian JJ, Bai DS, Li ZN, Jiang GQ and Yao J: Marital status independently predicts pancreatic cancer survival in patients treated with surgical resection: An analysis of the SEER database. Oncotarget 7: 24880-24887, 2016.

13. Sanda MG, Cadeddu JA, Kirkby E, Chen RC, Crispino T, Fontanarosa J, Freedland SJ, Greene K, Klotz LH, Makarov DV, et al: Clinically localized prostate cancer: AUA/ASTRO/SUO Guideline. Part I: Risk stratification, shared decision making, and care options. J Urol: Dec 14, 2017 (Epub ahead of print).

14. Mottet N, Bellmunt J, Bolla M, Briers E, Cumberbatch MG, De Santis M, Fossati N, Gross T, Henry AM, Joniau S, et al: EAU-ESTRO-SIOG guidelines on prostate cancer. Part 1: Screening, diagnosis, and local treatment with curative intent. Eur Urol 71: 618-629, 2017.

15. Cornford P, Bellmunt J, Bolla M, Briers E, De Santis M, Gross T, Henry AM, Joniau S, Lam TB, Mason MD, et al: EAU-ESTRO-SIOG guidelines on prostate cancer. Part II: Treatment of relapsing, metastatic, and castration-resistant prostate cancer. Eur Urol 71: 630-642, 2017.

16. Kravdal $\mathrm{H}$ and Syse A: Changes over time in the effect of marital status on cancer survival. BMC Public Health 11: 804, 2011.

17. Jaffe DH, Manor O, Eisenbach Z and Neumark YD: The protective effect of marriage on mortality in a dynamic society. Ann Epidemiol 17: 540-547, 2007.

18. Siegel RL, Miller KD and Jemal A: Cancer statistics, 2016. CA Cancer J Clin 66: 7-30, 2016.

19. Fritz A, Percy C, Jack A, Shanmugaratnam K, Sobin L, Parkin DM and Whelan S (eds): International Classification of Diseases for Oncology. 3rd edition. World Health Organization, Geneva, 2000.

20. Tefilli MV, Gheiler EL, Tiguert R, Sakr W, Grignon DJ, Banerjee M, Pontes JE and Wood DP Jr: Should Gleason score 7 prostate cancer be considered a unique grade category? Urology 53: 372-377, 1999.

21. Ohno Y, Ohori M, Nakashima J, Okubo H, Satake N, Hashimoto T and Tachibana M: Association between preoperative serum total cholesterol level and biochemical recurrence in prostate cancer patients who underwent radical prostatectomy. Mol Clin Oncol 4: 1073-1077, 2016.

22. Denberg TD, Beaty BL, Kim FJ and Steiner JF: Marriage and ethnicity predict treatment in localized prostate carcinoma. Cancer 103: 1819-1825, 2005.

23. Denberg TD, Glodé LM, Steiner JF, Crawford ED and Hoffman RM: Trends and predictors of aggressive therapy for clinical locally advanced prostate carcinoma. BJU Int $98:$ 335-340, 2006.

24. Kaiser NC, Hartoonian N and Owen JE: Toward a cancer-specific model of psychological distress: Population data from the 2003-2005 National Health Interview Surveys. J Cancer Surviv 4: 291-302, 2010.

25. DiMatteo MR, Lepper HS and Croghan TW: Depression is a risk factor for noncompliance with medical treatment: Meta-analysis of the effects of anxiety and depression on patient adherence. Arch Intern Med 160: 2101-2107, 2000. 
26. Forsythe LP, Alfano CM, Kent EE, Weaver KE, Bellizzi K, Arora N, Aziz N, Keel G and Rowland JH: Social support, self-efficacy for decision-making, and follow-up care use in long-term cancer survivors. Psychooncology 23: 788-796, 2014.

27. Gidron Y and Ronson A: Psychosocial factors, biological mediators, and cancer prognosis: A new look at an old story. Curr Opin Oncol 20: 386-392, 2008.

28. Garssen B: Psychological factors and cancer development: Evidence after 30 years of research. Clin Psychol Rev 24: 315-338, 2004.

29. Levy SM, Herberman RB, Whiteside T, Sanzo K, Lee J and Kirkwood J: Perceived social support and tumor estrogen/progesterone receptor status as predictors of natural killer cell activity in breast cancer patients. Psychosom Med 52: 73-85, 1990.

30. Antoni MH, Lutgendorf SK, Cole SW, Dhabhar FS, Sephton SE, McDonald PG, Stefanek M and Sood AK: The influence of bio-behavioural factors on tumour biology: Pathways and mechanisms. Nat Rev Cancer 6: 240-248, 2006.

31. Edge SB and Compton CC: The American Joint Committee on Cancer: The 7th edition of the AJCC cancer staging manual and the future of TNM. Ann Surg Oncol 17: 1471-1474, 2010.

32. Yang M, Kenfield SA, Van Blarigan EL, Batista JL, Sesso HD, Ma J, Stampfer MJ and Chavarro JE: Dietary patterns after prostate cancer diagnosis in relation to disease-specific and total mortality. Cancer Prev Res (Phila) 8: 545-551, 2015.

33. Kenfield SA, DuPre N, Richman EL, Stampfer MJ, Chan JM and Giovannucci EL: Mediterranean diet and prostate cancer risk and mortality in the health professionals follow-up study. Eur Urol 65: 887-894, 2014
34. Fossati N, Nguyen DP, Trinh QD, Sammon J, Sood A, Larcher A, Guazzoni G, Montorsi F, Briganti A, Menon M and Abdollah F: The impact of insurance status on tumor characteristics and treatment selection in contemporary patients with prostate cancer. J Natl Compr Canc Netw 13: 1351-1358, 2015.

35. Mahal BA, Aizer AA, Ziehr DR, Hyatt AS, Lago-Hernandez C, Chen YW, Choueiri TK, Hu JC, Sweeney CJ, Beard CJ, et al: The association between insurance status and prostate cancer outcomes: Implications for the affordable care act. Prostate Cancer Prostatic Dis 17: 273-279, 2014.

36. Polesel J, Gini A, Dal Maso L, Stocco C, Birri S, Taborelli M, Serraino D and Zucchetto A: The impact of diabetes and other metabolic disorders on prostate cancer prognosis. J Diabetes Complications 30: 591-596, 2016.

37. Armenian SH, Xu L, Ky B, Sun C, Farol LT, Pal SK, Douglas PS, Bhatia $\mathrm{S}$ and Chao $\mathrm{C}$ : Cardiovascular disease among survivors of Adult-onset cancer: A community-based retrospective cohort study. J Clin Oncol 34: 1122-1130, 2016.

38. Zist A, Amir E, Ocana AF and Seruga B: Impact of comorbidity on the outcome in men with advanced prostate cancer treated with docetaxel. Radiol Oncol 49: 402-408, 2015.

This work is licensed under a Creative Commons Attribution-NonCommercial-NoDerivatives 4.0 International (CC BY-NC-ND 4.0) License. 